\title{
A REFLEX EFFECT ON GLUCOSE RELEASE FROM THE LIVER OF THE TOAD
}

\author{
Akira NiIJIMA and Akiko FukudA \\ Department of Physiology, School of Medicine, Niigata University, Niigata, Japan
}

\begin{abstract}
Summary 1. The relationship between intra-aortic pressure and rate of efferent discharge in the hepatic branch of the splanchnic nerve, and release of glucose from the liver was studied in toad in vivo.

2. The inverse relationship between intra-aortic pressure and efferent discharge rate in the hepatic nerve as well as amount of glucose release from the liver was observed.

3. The existence of a blood sugar control mechanism due to the baroreceptor reflex through sympathetic innervation of the liver was suggested.
\end{abstract}

Spontaneous nerve impulses from pre- and postganglionic sympathetic fibers were first recorded by ADRIAN et al. (1932) in the early 1930's. These authors, later AlEXANDER (1945), and BRONK et al. (1936) noted that splanchnic, renal and cardiac postganglionic sympathetic discharges in rhythmic bursts synchronous to the heartbeat and respiratory movements. WEIDINGER and LESCHHORN (1964), KoIzUMI and SUDA (1963) reported that artificially forced fluctuations of systemic blood pressure were followed by a change in sympathetic nerve activity in an opposite direction, which means that the increase in blood pressure was followed by a decrease in sympathetic nerve activity and vice versa. They reported that these fluctuations in sympathetic output ceased after disruption of the carotid sinus and aortic depressor nerves. They concluded that the baroreceptors dominantly influence central sympathetic output. In 1968 it was further shown by KEZDI and GELLER (1968) that postganglionic splanchnic sympathetic discharge is controlled by baroreceptor input. Over the physiological range of pressure, the static response of the system can be approximated by a linear inverse relationship.

On the other hand, in 1970 it was shown by EDWARDS and SILVER (1970) that stimulation of the peripheral end of the splanchnic nerve rapidly depletes the reserve of glycogen in the liver and raises the concentration of glucose in the circulatory plasma of calves in which both adrenal glands had been removed.

Received for publication May 18, 1973

新島 旭, 福田昭子 
They concluded that this response is due to stimulation of the hepatic sympathetic innervation. EDWARDS $(1971,1972)$ further reported that the same response was also observed in pigs, sheep, dogs, and cats. Recently, NiIJIMA and FukUdA (1973) reported that release of glucose from the liver into the perfusion fluid occurred in response to splanchnic nerve stimulation in isolated liver preparation in toad.

The above-mentioned reports suggest that there might be a baroreceptor reflex effect on glucose release from the liver through hepatic sympathetic innervation. To study this mechanism experiments were conducted in toad in vivo.

\section{METHODS}

Animals of both sexes weighing $200-300 \mathrm{~g}$ were used. The animals were anaesthetized with urethane $(1 \mathrm{~g} / \mathrm{kg})$ injected subcutaneously and immobilized with gallamine $(300 \mathrm{mg} / \mathrm{kg})$ injected subcutaneously.

Efferent discharge of sympathetic fibers were recorded from the fine filaments dissected from hepatic branches of splanchnic nerve. Recordings were made with a $\mathrm{C}-\mathrm{R}$ amplifier (time constant, $0.003 \mathrm{sec}$ ) with a kymograph camera and stored on magnetic tape. All analysis of nervous activity took place after the conversion of raw data to standard pulses by a sensitive window discriminator which picked up discharges from background noise. The standard pulses were then fed into a small digital computer for further analysis. On-line analysis of discharge was also made.

To estimate the conduction velocity, square-wave electrical pulses of $1 \mathrm{msec}$ duration were applied to the splanchnic nerve through a pair of silver wire electrodes which were connected through an isolation unit to a stimulator (Nihonkohden, MSE-3).

Most of the experiments were conducted under the following circulatory conditions; several experiments conducted under normal circulatory conditions. After isolating the heart, a catheter was inserted into the aorta to perfuse the aorta and its branches with oxygenated Ringer solution from a reservoir. It was possible to change the perfusion pressure by changing the position of the reservoir within a range of 0 to $100 \mathrm{~cm} \mathrm{H}_{2} \mathrm{O}$. The perfusion pressure was recorded with a catheter connecting the perfusion system and electromanometer.

To observe the reflex effect on glucose release from the liver, a catheter was inserted into the portal vein. Oxygenated Ringer solution was delivered by a catheter from a Mariotte's bottle into the portal vein. The perfusion pressure was kept by $15 \mathrm{~cm} \mathrm{H}_{2} \mathrm{O}$ and the flow rate was kept for $2 \mathrm{ml} / \mathrm{min}$. The solution entered through the portal vein, was circulated in the liver, and exited through the hepatic vein. To estimate the content of glucose released from the liver into the perfusion fluid, a color reaction method (MOMOSE and INADA, 1961) using 3,6-dinitrophthalic acid was used. 


\section{RESULTS}

Effect of intravenous infusion of Ringer solution and haemorrhaging on efferent discharge in the sympathetic hepatic nerve

When the central end of a small filament dissected from hepatic branch of splanchnic nerve was placed on the recording electrode, spontaneous burst discharges were observed (Fig. 1, upper trace). Following intravenous infusion of $2 \mathrm{ml}$ Ringer solution a decrease in efferent discharge was observed (Fig. 1, middle trace). On the other hand, haemorrhaging from the abdominal aorta caused an remarkable increase in efferent nervous activity (Fig. 1, lower trace).

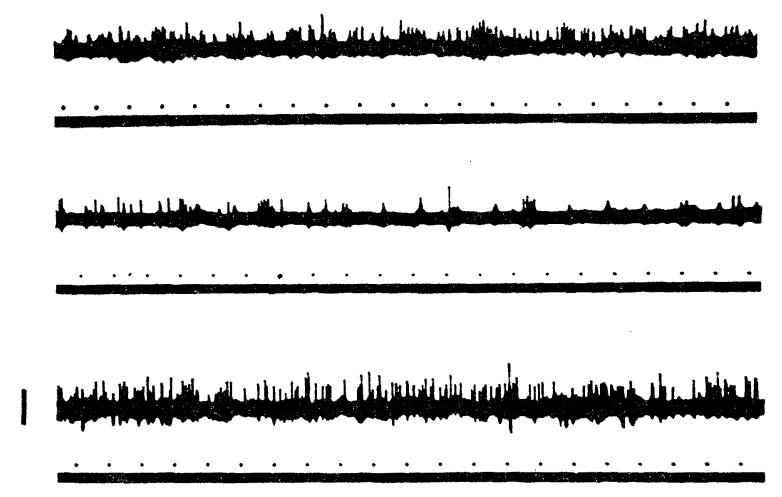

Fig. 1. Efferent discharge recorded from hepatic branch of the splanchnic nerve in toad in vivo. Upper trace, control. Middle trace, after infusion of $2 \mathrm{ml}$ Ringer solution. Lower trace, after haemorrhaging. Vertical bar, $100 \mu \mathrm{V}$. Time mark, $1 \mathrm{sec}$.

Following these experiments, splanchnic nerve trunks were cut and their peripheral ends were placed on the stimulation electrode to estimate the conduction velocity. The distance between the stimulation electrode and recording electrode placed on a hepatic branch was $40 \mathrm{~mm}$. The conduction velocity estimated in this preparation was $27 \mathrm{~cm} / \mathrm{sec}$ at about $20^{\circ} \mathrm{C}$.

\section{The relationship between perfusion pressure and efferent discharge rate}

After isolation of the heart a catheter was inserted into aorta to study the relationship between perfusion pressure and efferent discharge rate. Under perfusion by Ringer solution with constant pressure $\left(60 \mathrm{~cm} \mathrm{H}_{2} \mathrm{O}\right)$, consistent efferent discharges were recorded from a hepatic branch of splanchnic nerve. When the pressure was abruptly decreased from 60 to $30 \mathrm{~cm} \mathrm{H}_{2} \mathrm{O}$, rapid increase in discharge rate was observed; it reached to its maximal value about $10 \mathrm{sec}$ later. While the pressure level was kept at $30 \mathrm{~cm} \mathrm{H}_{2} \mathrm{O}$ for $50 \mathrm{sec}$, the discharge rate stayed at about the same level. When the pressure was suddenly returned to the previous level $\left(60 \mathrm{~cm} \mathrm{H}_{2} \mathrm{O}\right)$ and it was kept constant thereafter, a gradual decrease in efferent discharge rate was observed (Fig. 3, above). 


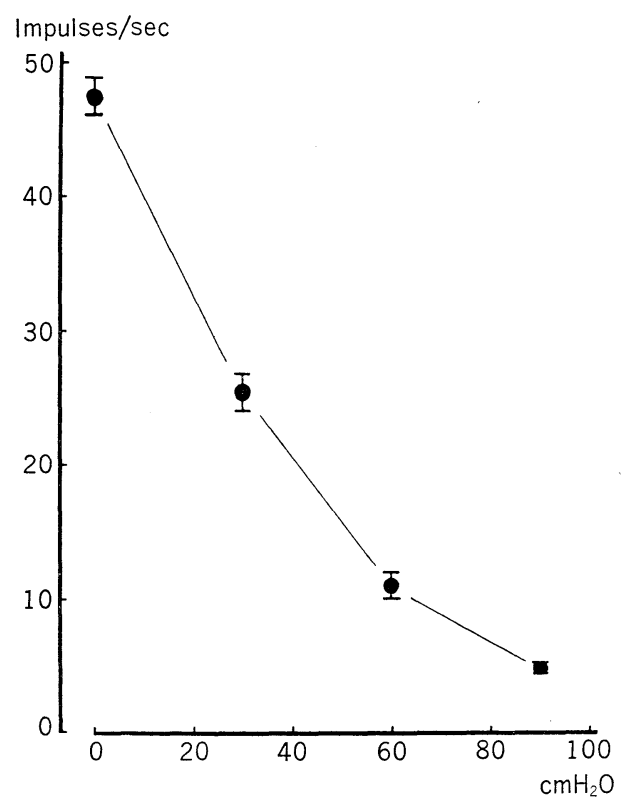

Fig. 2. Relationship between perfusion pressure and discharge rate in hepatic nerve.

Each point shows mean value with \pm S.E. of mean $(N=20)$.

In the next experiments, the relationship between perfusion pressure and efferent discharge rate was studied and plotted (Fig. 2) as shown in the figure; the mean discharge rate was $47.3 / \mathrm{sec}$ at $0 \mathrm{~cm} \mathrm{H}_{2} \mathrm{O}, 25.3 / \mathrm{sec}$ at $30 \mathrm{~cm} \mathrm{H}_{2} \mathrm{O}, 10.9 / \mathrm{sec}$ at $60 \mathrm{~cm} \mathrm{H} \mathrm{H}_{2} \mathrm{O}$ and $4.6 / \mathrm{sec}$ at $90 \mathrm{~cm} \mathrm{H}_{2} \mathrm{O}$. These mean values of efferent discharge rate were obtained from 20 measurements of $20 \mathrm{sec}$ epochs. It was observed that the higher the intra-aortic pressure, the lower the discharge rate.

The release of glucose from the liver in response to decrease in intra-aortic pressure

In the following experiments the aorta and its branches were perfused under a constant pressure $\left(60 \mathrm{~cm} \mathrm{H}_{2} \mathrm{O}\right)$ by the previously mentioned method. Then one end of a catheter was inserted into the portal vein to perfuse the liver and the other end of it was connected to a Mariotte's bottle. The perfusion system of the liver was completely separated from that of the body. Perfusion fluid emerging from the hepatic vein was collected to test for the glucose content. Blood vessels and other tissues connecting the liver and the body were cut and tied. After these procedures the liver and the body were connected only by splanchnic nerves.

When intra-aortic pressure was suddenly reduced from $60 \mathrm{~cm} \mathrm{H}_{2} \mathrm{O}$ to $30 \mathrm{~cm}$ $\mathrm{H}_{2} \mathrm{O}$, an increase in glucose content in the perfusion fluid was observed. Before the reduction in perfusion pressure the glucose concentration in perfusion fluid was $5 \mathrm{mg} / \mathrm{dl}$. After the reduction in pressure glucose concentration rapidly 

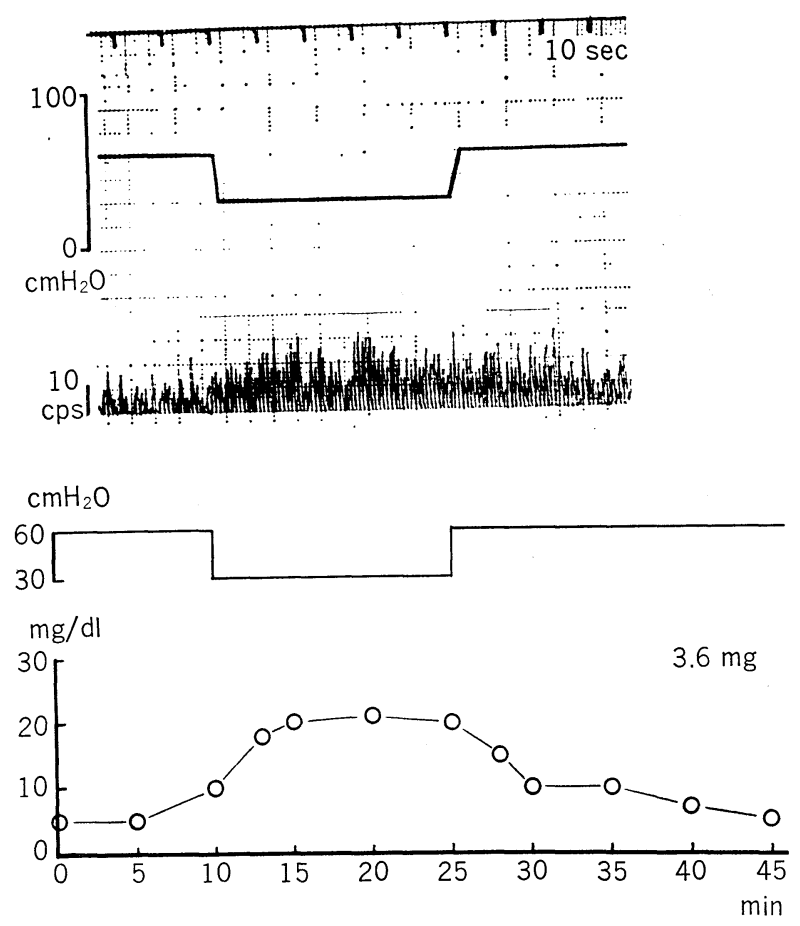

Fig. 3. Effect of reduction in perfusion pressure of aorta on firing rate of hepatic branch of splanchnic efferents, and on glucose concentration in perfusion fluid emerged from the liver. Upper graph shows the relationship between perfusion pressure and efferent discharge rate. Top, time mark, $10 \mathrm{sec}$. Middle, perfusion pressure. Lower trace, efferent discharge rate. Lower graph shows the relationship between perfusion pressure and concentration of glucose in the perfusion fluid collected from the hepatic vein. Upper trace, perfusion pressure. Lower trace, time course of glucose concentration in the perfusion fluid. Splanchnic nerve is the only connection between body and liver in this preparation.

increased. It reached $20 \mathrm{mg} / \mathrm{dl} 5 \mathrm{~min}$ later. While the perfusion pressure was kept constant at $30 \mathrm{~cm} \mathrm{H}_{2} \mathrm{O}$ for a further $10 \mathrm{~min}$, the glucose concentration stayed at about the same level. When the pressure was suddenly returned to the previous level $\left(60 \mathrm{~cm} \mathrm{H}_{2} \mathrm{O}\right)$ a gradual decrease in glucose concentration was observed. It returned to the control level $(5 \mathrm{mg} / \mathrm{dl}) 20 \mathrm{~min}$ later (Fig. 3, below).

The total amount of glucose released from the liver due to the reduction in perfusion pressure was $3.6 \mathrm{mg}$. This value was obtained from the perfusion fluid accumulated during and after the reduction in perfusion pressure. The increase in glucose concentration in the perfusion fluid during the reduction in intra-aortic pressure was also observed in another 8 animals out of 9. A toad which showed no increase in glucose content following the decrease in intra-aortic pressure might have had the hepatic nerve injured during the operation. 
A
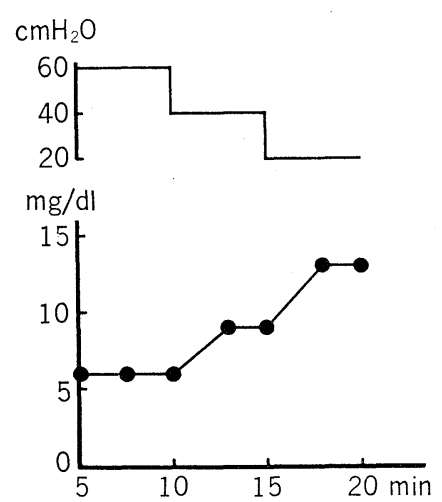

$\mathrm{mg} / \mathrm{dl} \quad \mathrm{B}$

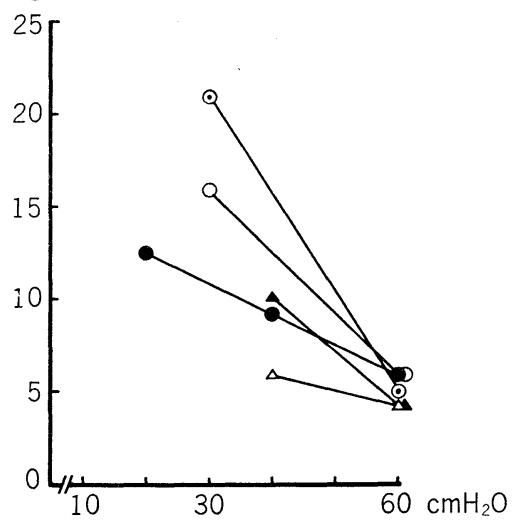

Fig. 4. Relationship between perfusion pressure and release of glucose from the liver. A: Upper curve, perfusion pressure. Lower curve, glucose concentration in the perfusion fluid. B: Vertical axis, glucose concentration. Horizontal axis, perfusion pressure. Five cases. Splanchnic nerve is the only connection between body and liver.

\section{The relationship between perfusion pressure and release of glucose}

In the following experiments the perfusion pressure was reduced stepwise, and the relationship between release of glucose from the liver and levels of perfusion pressure was studied. After keeping the pressure at $60 \mathrm{~cm} \mathrm{H}_{2} \mathrm{O}$ for $5 \mathrm{~min}$, the pressure was reduced to the level of $40 \mathrm{~cm} \mathrm{H}_{2} \mathrm{O}$ which was kept for $5 \mathrm{~min}$. Then it was further reduced to $20 \mathrm{~cm} \mathrm{H}_{2} \mathrm{O}$. The glucose concentration in the perfusion fluid was $6 \mathrm{mg} / \mathrm{dl}$ at $60 \mathrm{~cm} \mathrm{H}_{2} \mathrm{O}$. It increased to the level of $9 \mathrm{mg} / \mathrm{dl}$ 3 min later with the reduction in pressure to $40 \mathrm{~cm} \mathrm{H}_{2} \mathrm{O}$. Further reduction in perfusion pressure from 40 to $20 \mathrm{~cm} \mathrm{H}_{2} \mathrm{O}$ caused the increase in glucose concentration from $9 \mathrm{mg} / \mathrm{dl}$ to $13 \mathrm{mg} / \mathrm{dl} 3 \mathrm{~min}$ later (Fig. 4A). The relationship between perfusion pressure and concentration of glucose in the perfusion fluid emerging

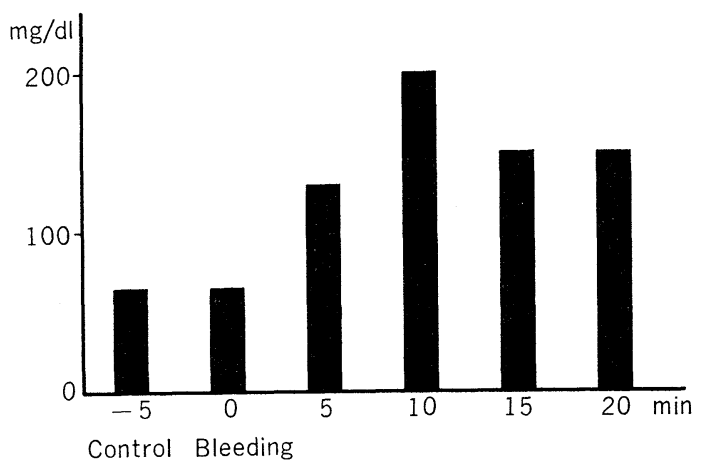

Fig. 5. Effect of haemorrhaging on glucose concentration in plasma. Blood vessels to both adrenal glands were tied. 
from the hepatic vein is presented in Fig. 4B. Data obtained from five experiments are shown.

\section{The effect of haemorrhage on blood sugar level in toad}

The following experiments were conducted to study the effect of haemorrhaging on glucose concentration in blood plasma. After ligation of blood vessels to both adrenal glands, a small hole was made in the wall of aorta to cause haemorrhaging. Glucose concentration in plasma was observed before, during and after haemorrhaging. Before and during haemorrhaging the value was $65 \mathrm{mg} / \mathrm{dl}$. After haemorrhaging it increased to $130 \mathrm{mg} / \mathrm{dl} 5 \mathrm{~min}$ later, it reached the maximal value $(200 \mathrm{mg} / \mathrm{dl}) 10 \mathrm{~min}$ later, then it gradually decreased to $150 \mathrm{mg} / \mathrm{dl}$ 20 min later (Fig. 5). It was clearly shown in the experiments that haemorrhaging caused an increase in plasma glucose concentration without contribution of the adrenal glands in toad in vivo. It is suggested that the increase in glucose concentration is due to its release from the liver.

\section{DISCUSSION}

As already described in the introduction a change in blood pressure changes sympathetic nervous activity. A report by KezDI and GeLLER (1968) noted that postganglionic splanchnic discharge is controlled by baroreceptor input. They stated that the static response of the system can be approximated by a linear inverse relationship. The authors' experimental results also showed the same type of inverse relationship between intra-aortic pressure and efferent discharge rate in the hepatic sympathetic nerve in toad.

The results shown in Fig. 3 indicate the following facts; first, a decrease in intra-aortic pressure caused an increase in efferent discharge rate in the hepatic nerve; second, a decrease in intra-aortic pressure also caused an increase in glucose concentration in perfusion fluid emerging from the hepatic vein.

In addition to the reports by EDWARDS $(1970,1971,1972)$ in mammals, recently NIIJIMA and FUKUDA (1973) observed the release of glucose from the liver in response to splanchnic nerve stimulation in the isolated liver preparation in toad.

The same effect might be expected when efferent sympathetic discharge in the hepatic nerve was activated by means of baroreceptor reflex. As the splanchnic nerve is the only connection between the liver and the body in this preparation (Figs. 3 and 4), the increase in glucose concentration in the perfusion fluid accompanied with the reduction of intra-aortic pressure can be explained in this light.

It was reported by DITTMER and GREBE (1959) that the systemic blood pressure in toad is about $48 \mathrm{mmHg}\left(65.3 \mathrm{~cm} \mathrm{H} \mathrm{H}_{2} \mathrm{O}\right)$. It can be stated that $60 \mathrm{~cm} \mathrm{H}_{2} \mathrm{O}$ by perfusion pressure would have been nearly at normal level, and $30 \mathrm{~cm}_{2} \mathrm{O}$ was the half of the normal blood pressure level. 
It was reported by JUNGREIS and HoOPER (1970) that the mean glucose concentration in blood plasma in Rana pipiens is $c a .40 \mathrm{mg} / \mathrm{dl}$. The present authors, in this study, found that in 5 animals the total volume of blood of toad is about $6 \mathrm{ml}$. This means $2.4 \mathrm{mg}$ glucose is resolved in $6 \mathrm{ml}$ of blood in a toad. The reduction in perfusion pressure from $60 \mathrm{~cm} \mathrm{H}_{2} \mathrm{O}$ to $30 \mathrm{~cm} \mathrm{H} \mathrm{H}_{2} \mathrm{O}$ for $15 \mathrm{~min}$ causes the release of $3.6 \mathrm{mg}$ glucose from the liver was shown in this paper. In a normal toad if the blood pressure is reduced from normal level $\left(\mathrm{ca} .60 \mathrm{~cm} \mathrm{H}_{2} \mathrm{O}\right)$ to the half, a release of glucose of about the same amount from the liver into $6 \mathrm{ml}$ of blood (total volume of the blood in a toad) is expected. This means that the total amount of the glucose increases from $2.4 \mathrm{mg}$ to $6.0 \mathrm{mg}$ in $6 \mathrm{ml}$ of blood. Owing to this, the glucose concentration increases to $100 \mathrm{mg} / \mathrm{dl}$ which is 2.5 times higher than normal value $(40 \mathrm{mg} / \mathrm{dl})$.

Further, the data in Fig. $4 \mathrm{~A}$ and $\mathrm{B}$ show that there is an inverse relationship between intra-aortic pressure and release of glucose from the liver.

SHImAzu and AmaKawa (1968) mentioned in their paper that there are two separate mechanisms in the liver for controlling phosphorylase activation and glycogenolysis, and that neural control by sympathetic nerves is much faster than hormonal control by catecholamine.

It is well known that the sympathetic nervous activity is controlled by the baroreceptor reflex. The experimental data suggest that the baroreceptor reflex controls not only the activity of the sympathetic nerve fibers such as vasoconstrictors but also blood sugar level through the sympathetic hepatic innervation. To establish this reflex mechanism further accurate studies should be done.

\section{REFERENCES}

Adrian, E. D., Bronk, D. W., and Phillips, G. (1932) Discharges in mammalian sympathetic nerves. J. Physiol., 74: 115-133.

Alexander, R. S. (1945) The effects of blood flow and anoxia on spinal cardiovascular centers. Am. J. Physiol., 143: 698-708.

Bronk, D. W., Ferguson, L. K., Margaria, R., and Solandt, D. Y. (1936) The activity of the cardiac sympathetic centers. Am. J. Physiol., 117: 237-249.

Dittmer, D. S. and Grebe, R. M. (1959) Handbook of Circulation. W. B. Saunders Co., Philadelphia and London, p. 109.

Edwards, A. V. (1971) The glycogenolytic response to stimulation of the splanchnic nerves in adrenalectomized calves, sheep, dogs, cats and pigs. J. Physiol., 213: 741-759.

EDWARDs, A. V. (1972) The hyperglycaemic response to stimulation of the hepatic sympathetic innervation in adrenalectomized cats and dogs. J. Physiol., 220: 697-710.

Edwards, A. V. and Silver, M. (1970) The glycogenolytic response to stimulation of the splanchnic nerves in adrenalectomized calves. J. Physiol., 211: 109-124.

Jungreis, A. M. and Hooper, A. B. (1970) The effects of long-term starvation and acclimation temperature on glucose regulation and nitrogen anabolism in the frog, rana pipiens. Comp. Biochem. Physiol., 32: 417-432.

Kezdi, P. and Geller, E. (1968) Baroreceptor control of postganglionic sympathetic nerve discharge. Am. J. Physiol., 214: 427-435.

KorzumI, K. and SudA, I. (1963) Induced modulations in autonomic efferent neuron activity. 
Am. J. Physiol., 205: 738-744.

Momose, T. and InADA, A. (1961) Mechanism of the color reaction of 3,6-dinitrophthalic acid with reducing sugars. Chem. Pharm. Bull., 9: 263-266.

NiIJIMA, A. and FukudA, A. (1973) The release of glucose from perfused liver preparation in response to stimulation of the splanchnic nerves in the toad. Jap. J. Physiol., 23: 497-508.

Shimazu, T. and Amakawa, A. (1968) Regulation of glycogen metabolism in liver by the autonomic nervous system. 3. Differential effects of sympathetic-nerve stimulation and of catecholamines on liver phosphorylase. Biochim. Biophys. Acta, 165: 349-356.

WeIDINGER, H. vON and LeschHORN, V. (1964) Sympathische Tonisierung und rhythmische Blutdruckschwankungen. Z. Kreislaufforsch., 53: 985-1002. 